\title{
A LÍNGUA ESCRITA PADRÃO CONTEMPORÂNEA NO BRASIL, EM PORTUGAL E EM ANGOLA: O GÊNERO ACADÊMICO
}

Claudio Cezar Henriques (UERJ)

Resumo: Este artigo apresenta parte da pesquisa desenvolvida na UERJ, com o apoio do CNPq. Intitula-se "Novos Estudos Geo-Históricos do Português: a modalidade escrita contemporânea" e adota critérios de seleção de textos que se ajustam quanto ao gênero, ao domínio discursivo e aos modos de organização textual. Subdivide-se em três campos principais, construídos e intitulados simétrica e coerentemente, a saber: (i) "O português em textos jornalísticos"; (ii) "O português em textos acadêmicos"; e (iii) "O português em textos literários". Este artigo analisa e compara a linguagem acadêmica presente nos livros $O$ Profissional Incomum, de André Portes, A Função Social do Direito de Autor, de Nuno Manuel Gonçalves, e $O$ Mundo Fantástico da Linguagem Desportiva, de Geraldo Quiala.

Palavras-chave: Língua Portuguesa; Geo-História; Padrão escrito contemporâneo.

Abstract: This paper presents part of the research developed at UERJ, with the support of CNPq. It is entitled "New Geo-Historical Studies of Portuguese: the contemporary written modality" and adopts text selection criteria that fit coherently in terms of textual genre, discursive domain and modes of organization. It is subdivided into three main fields, symmetrically and coherently constructed and titled, namely: (i) "Portuguese in journalistic texts"; (ii) "Portuguese in academic texts"; and (iii) "Portuguese in literary texts". This paper analyses and compares the language of the books $O$ Profissional Incomum by André Portes, $A$ Função Social do Direito de Autor by Nuno Manuel Gonçalves, and $O$ Mundo Fantástico da Linguagem Desportiva by Geraldo Quiala.

Keywords: Portuguese; Geohistory; Contemporary written pattern. 


\section{INTRODUÇÃO}

A língua é um organismo vivo, resultado de um processo contínuo de mudanças, de simplificações e de ampliações, de influências e de empréstimos, fenômenos que vão se estabelecendo ao longo do tempo e do espaço que ela percorre.

O Português é a língua de que somos coproprietários. Como brasileiros, podemos dizer que somos os maiores donos (mais de 210 milhões de habitantes) dessa "empresa linguística" chamada língua portuguesa. Entretanto, os "sócios fundadores" dessa empresa (os portugueses) e os demais acionistas (angolanos, moçambicanos, guineenses, cabo-verdianos, são-tomenses e timorenses, sobretudo) praticam e exercem os seus direitos de legítimos coproprietários, o que aponta para a responsabilidade que a nação brasileira tem diante da constatação de que falamos uma língua internacional, algo a ser tratado como uma questão de interesse comum a toda a comunidade lusofônica. Esses números, porém, tendem a passar por uma importante modificação, devida ao intenso ciclo de crescimento demográfico africano.

Estudo das Nações Unidas ${ }^{1}$ projeta uma grande reviravolta no cenário populacional dos países que têm o português como

1 https://population.un.org/wpp/ - World Population Prospects 
língua principal. O quadro seguinte ${ }^{2}$ mostra números que impressionam:

\begin{tabular}{|l|l|l|}
\hline PAís & POPULAÇÃO ATUAL & POPULAÇÃO EM 2050 \\
\hline Brasil & 212.559 .000 & 228.980 .000 \\
\hline Portugal & 10.197 .000 & 9.085 .000 \\
\hline Angola & 32.866 .000 & 77.420 .000 \\
\hline Moçambique & 31.255 .000 & 65.313 .000 \\
\hline Guiné-Bissau & 1.968 .000 & 3.557 .000 \\
\hline Timor-Leste & 1.318 .000 & 2.019 .000 \\
\hline Cabo Verde & 556.000 & 679.000 \\
\hline S. Tomé e Príncipe & 219.000 & 394.000 \\
\hline TOTAL & 290.938 .000 & 387.447 .000 \\
\hline
\end{tabular}

Esses números indicam que, em breve, o Brasil passará dos atuais $73 \%$ para $59 \%$ do total de falantes de português no mundo. A geo-história da língua portuguesa é, como se depreende, uma matriz que nos serve para organizar um pouco melhor a reflexão acerca de temas como indivíduo e sociedade, língua e nacionalidade, regionalização e globalização, etc.

O planejamento desta pesquisa adotou critérios de seleção de textos que se ajustam coerentemente quanto ao gênero, ao domínio discursivo e aos modos de organização textual (HENRIQUES, 2018, p.7-24). Subdividiu-se o corpus em três campos principais, construídos e intitulados simétrica

2 O quadro apresentado, inspirado no que está publicado em Geo-História do Português (HENRIQUES, 2019, p.16), atualiza os dados e integraliza a relação de países que têm o português como língua principal. 
e coerentemente, a saber: (a) "O português em textos jornalísticos"; (b) "O português em textos acadêmicos"; e (c) "O português em textos literários". O primeiro desses itens, por razões metodológicas, subdividiu-se em "gênero jornalístico diário" (jornais) e "gênero jornalístico semanal" (revistas).

A constituição do corpus investigado em cada campo teve essa exigência, ficando a escolha assim organizada:

CAMPo 1 (textos literários): seis romances, dois de cada nação, abrangendo autores masculinos e femininos nos três casos.

- Brasil: O Professor, de Cristóvão Tezza (Record, 2014) e Noites de Alface, de Vanessa Bárbara (Objetiva, 2013);

- Portugal: Madrugada Suja, de Miguel Sousa Tavares (Clube do Autor, 2013) // Lillias Fraser de Hélia Correia (Ed. Relógio d'Água, 2015);

- Angola: A Cidade e as Duas Órfãs Malditas, de Luís Fernando (Editorial Nzila, 2008) // Os Panos Brancos, de Maria Celestina Fernandes (União dos Escritores Angolanos, 2012). 
- CAMPO 2 (textos acadêmicos): seis obras voltadas para o ensino universitário ou para a discussão acadêmica, duas de cada país.

- Brasil: Dona Leopoldina: a história não contada, de Paulo Rezzutti (Ed. LeYa, 2017) // O Profissional Incomum, de André Portes (Ed. Best Business, 2017 - a 1ạ ed. é de 2016);

- Portugal: Inimigos de Salazar, de Irene Flunser Pimentel (Clube do Autor, 2018) // A Função Social do Direito de Autor, de Nuno Manuel da Silva Gonçalves (Ed. Princípia, 2018);

- Angola: O Mundo Fantástico da Linguagem Desportiva, de Geraldo Quiala (Ed. Mayamba, 2010) // Desenvolvimento e Resiliência Social em África: dinâmicas rurais de Cabinda-Angola, de João Milando (Imprensa Nacional de Angola, 2013) - obs.: Cabinda é uma das 18 províncias de Angola.

CAMPO 3 (textos jornalísticos): quatro publicações de cada país, abrangendo jornais diários e revistas semanais.

- Brasil: revistas semanais Carta Capital e Veja, jornais diários O Globo e Folha de S. Paulo;

- Portugal: revistas semanais Visão e Sábado, jornais diários Expresso e Público;

- Angola: revistas semanais Áfrika e Lux, jornais diários Jornal de Angola e Novo Jornal.

Como se vê, a pesquisa tomou como ponto de partida a realidade praticada por escrito em textos jornalísticos, acadêmicos e literários, reunindo um corpus formado por textos brasileiros, portugueses e angolanos, com a pretensão de averiguar em que níveis se manifestam a unidade e a diversidade da língua-padrão, a despeito da atribulada história de sua expansão na Europa e nos demais continentes. 
A investigação desse corpus contemporâneo inspirou-se no que Nelson Rossi (1980, p.43) chamou de "o equilíbrio entre o estudo da convergência e o da divergência linguística" e envolveu a conhecida discussão a respeito da unidade e da diversidade linguística.

O estudo da linguagem praticada nesse acervo nos permitiu analisar a presença do português prototípico, com a possível intervenção de traços locais que se manifestam em especial no léxico e nas marcas de oralidade - embora o critério adotado não previsse esse evento -, construindo uma espécie de entrelaçamento entre as três variedades. Pode-se concluir que, no corpus em análise, o português escrito contemporâneo em obras e publicações com esse feitio contribui mais para a tese da unidade do que da diversidade da língua.

A flexibilidade normativa ou liberdade normativa - de que falam Menéndez-Pidal (1964, p.7) e Celso Cunha (1985, p.8) - é uma característica essencial da língua portuguesa. Atribuo à nossa língua as mesmas menções que MenéndezPidal faz sobre a língua espanhola em artigo que se chama "El Español de Canarias". Como Celso Cunha também o fez, parece-me válido admitir que talvez seja possível "chegar ao reconhecimento de uma diversidade básica de normas linguísticas dentro da língua portuguesa, não só no campo 
léxico e no campo fonético, mas também no sintático". Para esses dois autores, o ensino do idioma, "concebido então como reflexão científica sobre um sistema e uma norma cujo conhecimento pré-científico se possui de antemão", obteria do usuário comum a correção linguística e o domínio das possibilidades expressivas da língua.

Ao mesmo tempo, a língua literária (e - acrescento por pertinência - a língua acadêmica e a língua jornalística), sustentada em cada caso sobre uma estrutura normativa sentida como própria, poderia se despojar "de todo lastro inoperante, ganhando em flexibilidade e naturalidade" para repetir os termos de Pidal e Cunha.

Considerando então o conceito de uma macrounidade, o português do Brasil "constitui uma microunidade, correspondente a um uso típico, por parte de toda a comunidade brasileira, mediante uma gradativa diferenciação", como afirma Edith Pimentel Pinto (1992, p.11). Por esse raciocínio, também é possível supor que há outras microunidades dentro da macrounidade do português, assim como que também há submicrounidades dentro das microunidades.

Comungo com essas hipóteses, já que a codificação de tais variabilidades normativas (micro- e submicro- unidades), 
"longe de atentar contra a unidade do idioma", contribuiria para estabelecer uma maior intercompreensão entre as diversas modalidades do português hoje em uso.

O quadro comparativo dos números populacionais que está reproduzido logo após o terceiro parágrafo desta Introdução mostra que Portugal tem um contingente menor e decrescente de habitantes. O português europeu, assim como o português brasileiro, está assentado, conquanto convivamos a todo instante com questionamentos a respeito das aproximações e dos afastamentos entre essas duas variedades. O caso de Angola é diferente, sobretudo por ser recente. Há, hoje em Angola mais de 32 milhões de habitantes. Nas áreas urbanas, o percentual de falantes do português chega a $85 \%$, enquanto na zona rural é de $49 \%$. Em casa, muitos angolanos falam mais do que uma língua, mas o português já é falado por cerca de $70 \%$ da população. Os $30 \%$ restantes falam mais de 10 línguas nacionais, do ramo banto, como o quicongo (8,2\%, no norte) e o quimbundo (7,8\%, no norte e no litoral central). O chócue é falado no interior central e no norte (6,54\%); no sul, entre as províncias do Cuando-Cubango, Cunene e Huíla, falam-se as línguas ganguela $(3,11 \%)$, cuanhama $(2,26 \%)$ e muhumbi $(2,12 \%)$. Por fim, há ainda o fiote, língua falada no enclave de Cabinda por 2,4\% da população. 
O português é ensinado em todas as escolas de Angola. Em algumas delas, convive com o ensino das línguas nacionais, que dispõem de material pedagógico, mas sofrem com a falta de professores. Esse panorama de desigualdade é agravado pelo fato de ainda persistir em muitas famílias a carga negativa da língua local, criada no tempo da colonização, o que as faz preferirem que os filhos aprendam apenas português. Muitos receiam que o tempo gasto para estudar formalmente a língua local/nacional prejudique as atividades escolares restantes e por isso optam apenas pelo idioma oficial. Também contribui para essa situação a supremacia da população jovem, com menos de 24 anos, que - como diz Joana Gorjão Henriques (2017, p.24) "não viveu o período de apartheid social em Angola, mesmo que não oficial".

Bonifácio Tchimboto, pesquisador angolano, lembra que, para muitos de seus conterrâneos permanece a memória da placa de madeira pendurada nos estudantes flagrados, no tempo colonial português, falando quimbundo, uma das línguas nacionais angolanas. A inscrição dizia: BURRO. E acrescenta: "Essa carga pesada sobrevive ainda hoje na cabeça de muitos. Temos entre os nossos concidadãos aqueles que olham para o bilinguismo como um defeito, que a competência em duas línguas é um defeito.". Por 
isso, muitos dizem que não se deve usar nenhuma língua africana em público. Além disso, parece difícil encontrar, especialmente na população mais jovem, alguém que não fale ou, pelo menos, não compreenda o português. Isso faz de Angola praticamente uma exceção na África, já que, salvo alguns estados insulares, é o único país africano onde a língua europeia colonizadora é proeminente (cf. HODGES, 2002 , p.145) junto às massas populares.

Outro fator que importa na apresentação do contexto em que a língua portuguesa se consolida como a principal língua de Angola é o fato de a Constituição da República de Angola estabelecer, no seu artigo 19, item 1, que a língua portuguesa é a língua oficial do país, o que implica sua obrigatoriedade em todos os momentos da vida civil. Já as demais línguas locais são denominadas "línguas angolanas", sem o mesmo estatuto que a língua portuguesa.

Art. 19 (Línguas)

1. A língua oficial da República de Angola é o português.

2. O Estado valoriza e promove o estudo, o ensino e a utilização das demais línguas de Angola, bem como das principais línguas de comunicação internacional.

Art. 21 (Tarefas fundamentais do Estado)

(n) Proteger, valorizar e dignificar as línguas angolanas de origem africana, como património cultural, e promover o 
seu desenvolvimento, como línguas de identidade nacional e de comunicação.

Artigo 23 (Princípio da igualdade)

2. Ninguém pode ser prejudicado, privilegiado, privado de qualquer direito ou isento de qualquer dever em razão da sua ascendência, sexo, raça, etnia, cor, deficiência, língua, I ocal d e $\mathrm{n}$ ascimento, religião, convicções políticas, ideológicas ou filosóficas, grau de instrução, condição económica ou social ou profissão. (WIPO, 2010, p.9-11, grifo nosso)

Independentemente desse histórico e desses dados, as interferências linguísticas resultantes do contato do português com as línguas angolanas pré-existentes revelam a presença de substratos africanos no português de Angola, pois a língua do colonizador se impôs pelo maior prestígio cultural e social, mas os vários reinos locais, embora vencidos, deixaram marcas de seus hábitos linguísticos na língua nova. Ficaram substratos quimbundos, quicongos, chócues, etc.

Essa contribuição dá-se pela entrada de palavras africanas no léxico geral, pela criação de formas oriundas do gênio inventivo do homem comum, pelos desvios e adaptações da norma padrão europeia, permitindo que se sinta nesses usos sua adaptação à realidade linguística angolana. 


\section{O GÊNERO ACADÊMICO: RELATO DE UMA EXPERIÊNCIA}

No segundo semestre de 2019, preparei um protótipo de material para uso em sala de aula e em oficinas para professores. Descrevo, a seguir, uma dessas atividades.

Digo no enunciado:

Os três textos seguintes são oriundos de páginas de livros acadêmicos e se enquadram, predominantemente, no modo de organização expositivo-argumentativo, pois foram retirados de obras produzidas por profissionais que atuam no ambiente universitário. As fontes provêm destes três países: Angola, Brasil e Portugal. Cada texto aborda um tema que suponho ser isento de marcação nacional, a saber: o comportamento dos torcedores de futebol, a construção do sucesso na carreira profissional e a função social do Direito. Isso dá a entender que, a princípio, eles poderiam ser veiculados em qualquer dos países citados.

Os textos estão apresentados em ordem cronológica e mostram uma versão a que se chamou "neutralizada", pois estão expostos a partir da adoção de uma preferência ortográfica brasileira, com pequenos retoques nas ocorrências em que itens lexicais poderiam revelar a proveniência de algum deles.

O objetivo desta atividade é apresentar dados que possam confirmar a hipótese de que a língua-padrão escrita contemporânea - neste caso, no domínio acadêmico contém mais elementos unificadores do que diversificadores. Por isso, o que se propõe 
aos participantes é um exame dos três textos, que estão totalmente desidentificados, "neutralizados" - como se disse - de suas características superficiais nacionais (ortografia e léxico). As perguntas são: qual deles é angolano? qual deles é brasileiro? qual deles é lusitano?

\section{Três textos: versão "neutralizada”}

TEXTO I - de O Mundo Fantástico da Linguagem Desportiva:

\section{A Paixão pelo Esporte}

As rivalidades são sadias enquanto alimentam a disputa desportiva e levam atletas e adeptos a se manifestarem de forma respeitosa em relação aos clubes que defendem tanto quanto no que toca as outras equipes.

A partir do momento em que deixa de existir o respeito pelo próximo em função de nossas paixões clubísticas se perde qualquer razão e deixamo-nos levar, muitas vezes, para situações que são constrangedoras, embaraçosas e, em alguns casos, até mesmo trágicas.

As constantes agressões sofridas por torcedores, o confronto entre fãs mais exaltados, as mortes ocorridas em estádios ou mesmo os insultos usuais devem ser abolidos do esporte. As brincadeiras existem e fazem parte de uma relação que pode ser considerada natural desde que não ocorram os excessos. Torcer a favor do futebol e do esporte em geral, seja por qual clube for, deve continuar a ser o grande propósito.

Nenhuma paixão desportiva deve superar os direitos essenciais que cada ser humano possui, especialmente sua vida, suas liberdades individuais e também sua integridade física. 
Afinal de contas, o que diferencia os fãs? A cor das camisas, os jogadores que envergam os uniformes dos plantéis? A forma como se organizam as equipes para desenvolver o seu jogo? Os títulos e troféus conquistados? O que queremos quando assistimos a um jogo de futebol? Será que as pessoas vão aos estádios para brigar e não para torcer? Quem, entre nós, em sã consciência, vai a uma casa de espetáculos com o intuito de ser ofendido ou agredido, de insultar ou atacar a integridade de outras pessoas?

O problema das claques não é só uma questão em nosso país. Há racismo, hooligans e, consequentemente, agressões e palavras de baixo nível em várias partes do mundo. É uma situação que se agrava em determinados países e períodos em virtude da ação desmedida e absurda de alguns poucos torcedores ou de grupos que se autointitulam organizados e que pensam falar em nome de toda a massa que gosta desse esporte e das agremiações do futebol

Não nos sentimos representados por nenhuma das grandes claques uniformizadas do clube pelo qual torcemos. Não damos autorização para que ninguém desses grupos de torcedores fale em nosso nome. Acreditamos, sinceramente, que muitas pessoas deixam de ir ao estádio em função da violência que impera nas arquibancadas. Não temos coragem de expor os nossos familiares aos humores de uma turma destemperada por maus resultados ou por eventuais fracassos que podem acometer qualquer equipe do mundo.

TEXTO II - de O Profissional Incomum:

A Importância da Observação

Ao longo de minha vida profissional, tive oportunidade de viajar bastante, conhecer muitas pessoas, diversos lugares, organizações e empresas. Diante dessas experiências, 
pude desenvolver uma característica que sempre foi muito importante para mim: a observação. Ser um observador permitiu condicionar minha mente na busca do futuro com que sempre sonhei.

Decidi observar as pessoas que eram como eu queria ser, tinham o que eu queria ter, alcançaram o que eu gostaria de alcançar. Queria aprender como elas se comportavam, falavam, se vestiam, quais eram suas posturas, seus interesses, suas crenças, suas atitudes, o que estudavam, o que as inspirou e desejavam conhecer.

Foi importante entender desde cedo que existem milhares de pessoas muito melhores do que eu e que era necessário aprender com elas. Hoje, muita coisa mudou na minha vida; é claro que não atingi tudo o que gostaria, mas consegui realizar vários sonhos importantes. Devo muitas dessas conquistas aos aprendizados que tive observando pessoas que alcançaram o sucesso.

Em minhas observações, uma das maiores lições que aprendi é que em todo lugar, em organizações, universidades, instituições, na sociedade, existem três tipos de pessoas, três tipos de profissionais, três tipos de alunos, três tipos de trabalhadores, três tipos de pais, três tipos de amigos. São eles: os medíocres; os normais ou bons; e os excelentes ou acima da média. Essa constatação parece óbvia; entretanto, comecei uma pesquisa perguntando: por quê? Por que tantas diferenças? Por que você que está lendo este livro não duvida, mas reconhece o que acabei de relatar como verdade? Por que tem que ser assim? Por que um trabalhador é medíocre? Por que é simplesmente bom? E por que é excelente? Encontrei muitas respostas. A sociologia, a filosofia, a antropologia, a psicologia, a política e a religião têm suas respostas - boas respostas, convincentes. Porém, foi fácil descobrir que as respostas não 
mudam essa realidade. Aprendi que, mesmo conhecendo e encontrando respostas importantes e decisivas para a vida, ninguém muda a própria realidade sem uma vontade genuína que nasça dentro de si. Tudo o que entra em nossa mente pode ou não ser processado, pensado ou refletido. Caso haja uma necessidade ou um desejo de mudança, sem vontade será apenas um aprendizado estacionado e logo esquecido dentro de nós.

Também descobri que existe um problema que complica ainda mais a transformação desse quadro. A maior parte dos profissionais nem se dá conta de como é classificada. Não mudamos quando nada incomoda ou dói. Neste livro, apresento reflexões e exemplos do que pode ser feito para implementar mudanças significativas na vida de um profissional.

TEXTO III - de A Função Social do Direito de Autor:

Breve Referência à Função Social do Direito

É comum a atribuição ao Direito de uma irrecusável dimensão social, constituindo uma ordem da sociedade. O Direito é um fenômeno humano, relacional, cultural, visando a justiça como fim primeiro desde Roma e Atenas, não como uma simples emergência da natureza. [...] Como sintetiza A. Braz Teixeira, "a conduta ou o comportamento de que o Direito se ocupa e que procura regular e ordenar é a que tem que ver com a condição social do homem, com as suas relações com os outros homens e com as coisas, na medida em que estas últimas relações possam interessar ou afetar os outros". Esta visão do Direito tinha já sido delineada na Antiguidade Clássica, por filósofos como Aristóteles, ou na Idade Média por São Tomás de Aquino [...]. Todos os ordenamentos jurídicos partilham este caráter 
relacional. As relações pessoais no seio de uma sociedade constituem a referência básica de qualquer discurso jurídico. Por isso Hegel pôde escrever: "Sê uma pessoa e respeita os outros como pessoas." Daí que, modernamente, e após um percurso histórico que começou por repensar o valor e a função da propriedade, todo o Direito, toda a ordem jurídica, toda a norma seja interpretada pela visão correspondente à sua função social. Pode dizer-se que estamos perante a emergência de um novo paradigma jurídico.

A dimensão social do Direito exprime-se de um modo valorativo, fundamental, mediante o conceito de bem comum. Este deve ser interpretado em múltiplas dimensões e visar o recíproco condicionamento e a recíproca penetração entre o bem individual e o bem comum. $O$ princípio da função social do Direito constitui-se como uma espécie de cláusula geral- que nos permite pensar as soluções jurídicas a dar aos problemas sociais que careçam de intervenções jurídicas, umas vezes com uma perspectiva corretora de disfuncionalidades dos institutos jurídicos, outras vezes desbravando caminhos novos, em ordem a fazer prevalecer intervenções mais adequadas à promoção dos interesses públicos envolvidos. Trata-se de um desafio, em especial lançado aos juristas, na mira de se construir um Direito mais justo, realmente inserido nas tramas sociais, buscando soluções novas e equitativas para os problemas vividos.

O princípio da função social é imanente ao Direito, pelo que toda a norma jurídica espelha ou deve espelhar, de algum modo, a sua vivificadora existência. Por razões que indicamos infra, o princípio da função social tem sofrido um obscurecimento de tratamento no mundo do Direito, aspecto que alguma doutrina mais recente procura alterar, 
com ponderosas razões. Ao longo deste texto procuramos analisar a presença do referido princípio quer na legislação nacional relativa ao Direito de Autor, quer nos principais instrumentos internacionais multilaterais, incluindo os mais significativos documentos relativos aos direitos humanos, bem como textos constitucionais. A abordagem é realizada mediante a análise de tópicos essenciais caracterizadores de matérias estruturais do domínio do Direito de Autor. O caminho analítico é percorrido com recurso a alguma da mais significativa doutrina, e, pontualmente, da jurisprudência relevante. Interessa-nos salientar as dimensões, positiva e negativa, ou seja, o modo como o Direito de Autor se construiu historicamente como incentivo fundamental à criação cultural, bem como discernir a existência de limites e exceções aos exclusivos legais estabelecidos.

Três textos: versão original X versão “neutralizada"

TEXTO I - Angola: O Mundo Fantástico da Linguagem Desportiva, de Geraldo Quiala (2010, p.32-33)

A Paixão pelo Desporto

3 Geraldo Quiala é jornalista da Agência Angola Press, licenciado em Ciência da Educação pela Universidade Agostinho Neto. O livro é uma adaptação de sua tese de licenciatura em linguística. 
VERSÃO ORIGINAL

As rivalidades são sadias enquanto alimentam a disputa desportiva e levam atletas e adeptos a se manifestarem de forma respeitosa em relação aos clubes que defendem tanto quanto no que toca as outras equipas.

A partir do momento em que deixa de existir o respeito pelo próximo em função de nossas paixões clubísticas se perde qualquer razão e deixamo-nos levar, muitas vezes, para situações que são constrangedoras, embaraçosas e, em alguns casos, até mesmo trágicas.

As constantes agressões sofridas por apoiantes, o confronto entre fãs mais exaltados, as mortes ocorridas em estádios ou mesmo os insultos usuais devem ser abolidos do desporto. As brincadeiras existem e fazem parte de uma relação que pode ser considerada natural desde que não ocorram os excessos. Torcer a favor do futebol e do desporto em geral, seja por qual clube for, deve continuar a ser o grande propósito.

Nenhuma paixão desportiva deve superar os direitos essenciais que cada ser humano possui, especialmente sua vida, suas liberdades individuais e também sua integridade física.

Afinal de contas, o que diferencia os adeptos? A cor das camisolas, os jogadores que envergam os uniformes dos plantéis? A forma como se organizam as equipas para desenvolver o seu jogo? Os títulos e troféus conquistados? 0 que queremos quando assistimos a um jogo de futebol? Será que as pessoas vão aos estádios para brigar e não para torcer? Quem, entre nós, em sã consciência, vai a uma casa de espectáculos com o intuito de ser ofendido ou agredido, de insultar ou atacar a integridade de outras pessoas?

O problema das claques não é só uma questão angolana, portuguesa ou brasileira. Há racismo, hooligans e, consequentemente, agressões e palavras de baixo nível em várias partes do mundo. É uma situação que se agrava em determinados países e períodos em virtude da acção desmedida e absurda de alguns poucos apoiantes ou de grupos que se auto-intitulam adeptos organizados e que pensam falar em nome de toda a massa que gosta desse desporto e das agremiações do futebol

Não nos sentimos representados por nenhuma das grandes claques uniformizadas do clube pelo qual torcemos. Não damos autorização para que ninguém desses grupos de torcedores fale em nosso nome. Acreditamos, sinceramente, que muitas pessoas deixam de ir ao estádio em função da violência que impera nas arquibancadas. Não temos coragem de expor os nossos familiares aos humores de uma turma destemperada por maus resultados ou por eventuais fracassos que podem acometer qualquer equipa do mundo.
VERSÃO “NEUTRALIZADA"

As rivalidades são sadias enquanto alimentam a disputa desportiva e levam atletas e adeptos a se manifestarem de forma respeitosa em relação aos clubes que defendem tanto quanto no que toca as outras equipes.

A partir do momento em que deixa de existir o respeito pelo próximo em função de nossas paixões clubísticas se perde qualquer razão e deixamo-nos levar, muitas vezes, para situações que são constrangedoras, embaraçosas e, em alguns casos, até mesmo trágicas.

As constantes agressões sofridas por torcedores, o confronto entre fãs mais exaltados, as mortes ocorridas em estádios ou mesmo os insultos usuais devem ser abolidos do esporte. As brincadeiras existem e fazem parte de uma relação que pode ser considerada natural desde que não ocorram os excessos. Torcer a favor do futebol e do esporte em geral, seja por qual clube for, deve continuar a ser o grande propósito.

Nenhuma paixão desportiva deve superar os direitos essenciais que cada ser humano possui, especialmente sua vida, suas liberdades individuais e também sua integridade física.

Afinal de contas, o que diferencia os fãs? A cor das camisas, os jogadores que envergam os uniformes dos plantéis? A forma como se organizam as equipes para desenvolver o seu jogo? Os títulos e troféus conquistados? O que queremos quando assistimos a um jogo de futebol? Será que as pessoas vão aos estádios para brigar e não para torcer? Quem, entre nós, em sã consciência, vai a uma casa de espetáculos com o intuito de ser ofendido ou agredido, de insultar ou atacar a integridade de outras pessoas?

O problema das claques não é só uma questão em nosso país. Há racismo, hooligans e, consequentemente, agressões e palavras de baixo nível em várias partes do mundo. É uma situação que se agrava em determinados países e períodos em virtude da ação desmedida e absurda de alguns poucos torcedores ou de grupos que se autointitulam organizados e que pensam falar em nome de toda a massa que gosta desse esporte e das agremiações do futebol

Não nos sentimos representados por nenhuma das grandes claques uniformizadas do clube pelo qual torcemos. Não damos autorização para que ninguém desses grupos de torcedores fale em nosso nome. Acreditamos, sinceramente, que muitas pessoas deixam de ir ao estádio em função da violência que impera nas arquibancadas. Não temos coragem de expor os nossos familiares aos humores de uma turma destemperada por maus resultados ou por eventuais fracassos que podem acometer qualquer equipe do mundo. 


\section{TEXTO II - Brasil: O Profissional Incomum, de André Portes}

\section{(2017, p.11-12)}

\section{A Importância da Observação ${ }^{4}$}

\begin{tabular}{|c|c|}
\hline VERSÃO ORIGINAL & VERSÃo “NEUTRALIZADA” \\
\hline 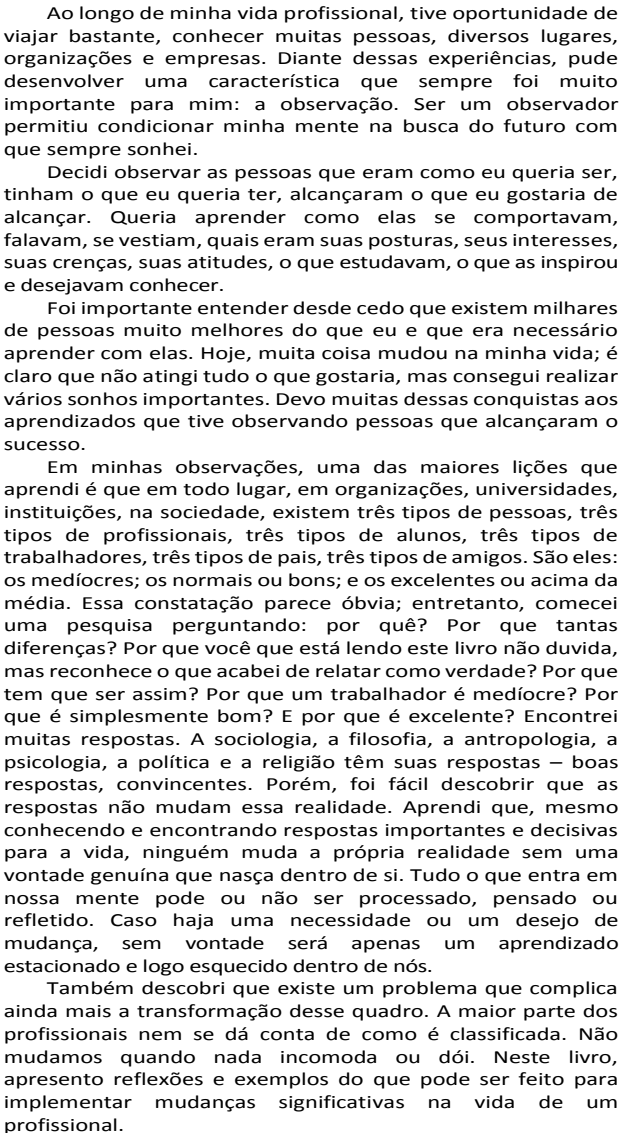 & 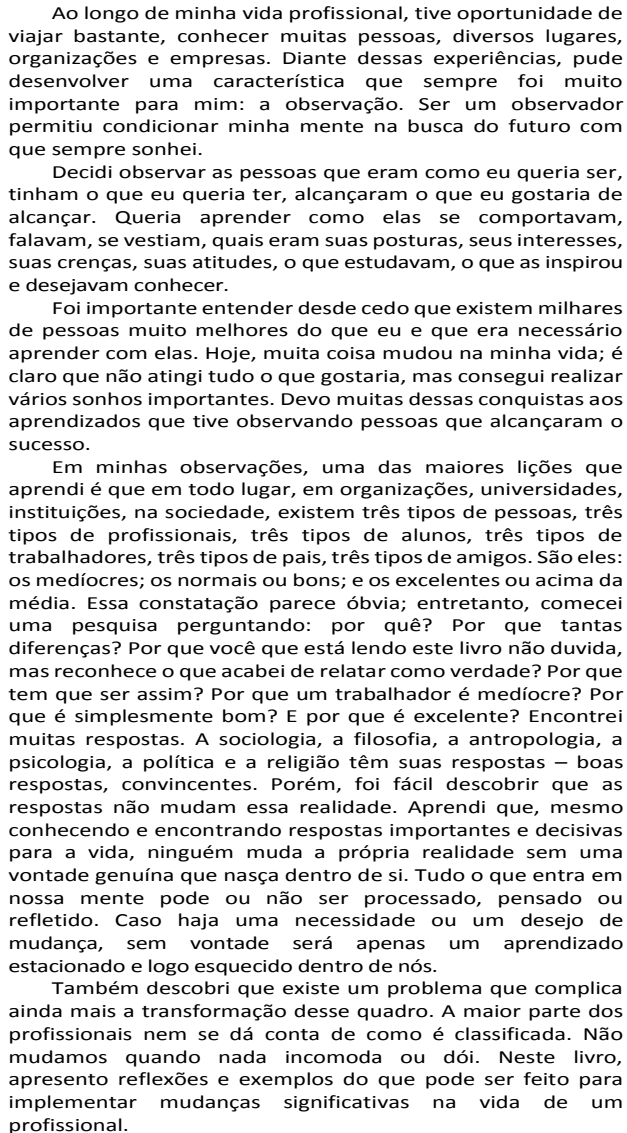 \\
\hline
\end{tabular}

4 O trecho, que no original não tem título, é o que inicia a Introdução do livro. ANDRÉ PORTES é administrador de empresas com MBA Executivo em Gestão Empresarial Estratégica de Negócios pela USP e MBA em Marketing pela COPPEAD - UFRJ. Desde 2011 atua como consultor e professor em universidades, empresas e associações nas disciplinas de Marketing, Negociação, Liderança, Inteligência Emocional e Análise de Cenários. O livro é resultado das experiências como conferencista e palestrante. 
TEXTO III - Portugal: A Função Social do Direito de Autor, de Nuno Gonçalves (2018, p.13-16)

Breve Referência à Função Social do Direito ${ }^{5}$

50 trecho é o que inicia o livro. Nuno Gonçalves é consultor da Direção-Geral do Livro, dos Arquivos e das Bibliotecas, órgão oficial do governo português, O livro corresponde, com ligeiras alterações, à dissertação de Mestrado defendida na Faculdade de Direito da Universidade de Lisboa, em 2016. 
VERSÃO ORIGINAL

É comum a atribuição ao Direito de uma irrecusável dimensão social, constituindo uma ordem da sociedade. O Direito é um fenómeno humano, relacional, cultural, visando a justiça como fim primeiro desde Roma e Atenas, não como uma simples emergência da natureza. [...] Como sintetiza A. Braz Teixeira, "a conduta ou o comportamento de que o Direito se ocupa e que procura regular e ordenar é a que tem que ver com a condição social do homem, com as suas relações com os outros homens e com as coisas, na medida em que estas últimas relações possam interessar ou afetar os outros". Esta visão do Direito tinha já sido delineada na Antiguidade Clássica, por filósofos como Aristóteles, ou na Idade Média por São Tomás de Aquino [...]. Todos os ordenamentos jurídicos partilham este caráter relacional. As relações pessoais no seio de uma sociedade constituem a referência básica de qualquer discurso jurídico. Por isso Hegel pôde escrever: "Sê uma pessoa e respeita os outros como pessoas.". Daí que, modernamente, e após um percurso histórico que começou por repensar o valor e a função da propriedade, todo o Direito, toda a ordem jurídica, toda a norma seja interpretada pela visão correspondente à sua função social. Pode dizer-se que estamos perante a emergência de um novo paradigma jurídico.

\section{$[\ldots]$}

A dimensão social do Direito exprime-se de um modo valorativo, fundamental, mediante o conceito de bem comum. Este deve ser interpretado em múltiplas dimensões e visar o recíproco condicionamento e a recíproca penetração entre o bem individual e o bem comum. O princípio da função social do Direito constitui-se como uma espécie de ·cláusula geral· que nos permite pensar as soluções jurídicas a dar aos problemas sociais que careçam de intervenções jurídicas, umas vezes com uma perspetiva corretora de disfuncionalidades dos institutos jurídicos, outras vezes desbravando caminhos novos, em ordem a fazer prevalecer intervenções mais adequadas à promoção dos interesses públicos envolvidos. Trata-se de um desafio, em especial lançado aos juristas, na mira de se construir um Direito mais justo, realmente inserido nas tramas sociais, buscando soluções novas e equitativas para os problemas vividos.

O princípio da função social é imanente ao Direito, pelo que toda a norma jurídica espelha ou deve espelhar, de algum modo, a sua vivificadora existência. Por razões que indicamos infra, o princípio da função social tem sofrido um obscurecimento de tratamento no mundo do Direito, aspeto que alguma doutrina mais recente procura alterar, com ponderosas razões. Ao longo deste texto procuramos analisar a presença do referido princípio quer na legislação nacional relativa ao Direito de Autor, quer nos principais instrumentos internacionais multilaterais, incluindo os mais significativos documentos relativos aos direitos humanos, bem como textos constitucionais. A abordagem é realizada mediante a análise de tópicos essenciais caracterizadores de matérias estruturais do domínio do Direito de Autor. O caminho analítico é percorrido com recurso a alguma da mais significativa doutrina, e, pontualmente, da jurisprudência relevante. Interessa-nos salientar as dimensões, positiva e negativa, ou seja, o modo como o Direito de Autor se construiu historicamente como incentivo fundamental à criação cultural, bem como discernir a existência de limites e exceções aos exclusivos legais estabelecidos.
VERSÃO “NEUTRALIZADA"

É comum a atribuição ao Direito de uma irrecusável dimensão social, constituindo uma ordem da sociedade. O Direito é um fenômeno humano, relacional, cultural, visando a justiça como fim primeiro desde Roma e Atenas, não como uma simples emergência da natureza. [...] Como sintetiza A. Braz Teixeira, "a conduta ou o comportamento de que o Direito se ocupa e que procura regular e ordenar é a que tem que ver com a condição social do homem, com as suas relações com os outros homens e com as coisas, na medida em que estas últimas relações possam interessar ou afetar os outros". Esta visão do Direito tinha já sido delineada na Antiguidade Clássica, por filósofos como Aristóteles, ou na Idade Média por São Tomás de Aquino [...]. Todos os ordenamentos jurídicos partilham este caráter relacional. As relações pessoais no seio de uma sociedade constituem a referência básica de qualquer discurso jurídico. Por isso Hegel pôde escrever: "Sê uma pessoa e respeita os outros como pessoas.". Daí que, modernamente, e após um percurso histórico que começou por repensar o valor e a função da propriedade, todo o Direito, toda a ordem jurídica, toda a norma seja interpretada pela visão correspondente à sua função social. Pode dizer-se que estamos perante a emergência de um novo paradigma jurídico.

$[\ldots]$

A dimensão social do Direito exprime-se de um modo valorativo, fundamental, mediante o conceito de bem comum. Este deve ser interpretado em múltiplas dimensões e visar o recíproco condicionamento e a recíproca penetração entre o bem individual e o bem comum. O princípio da função social do Direito constitui-se como uma espécie de ·cláusula geral que nos permite pensar as soluções jurídicas a dar aos problemas sociais que careçam de intervenções jurídicas, umas vezes com uma perspectiva corretora de disfuncionalidades dos institutos jurídicos, outras vezes desbravando caminhos novos, em ordem a fazer prevalecer intervenções mais adequadas à promoção dos interesses públicos envolvidos. Trata-se de um desafio, em especial lançado aos juristas, na mira de se construir um Direito mais justo, realmente inserido nas tramas sociais, buscando soluções novas e equitativas para os problemas vividos.

O princípio da função social é imanente ao Direito, pelo que toda a norma jurídica espelha ou deve espelhar, de algum modo, a sua vivificadora existência. Por razões que indicamos infra, o princípio da função social tem sofrido um obscurecimento de tratamento no mundo do Direito, aspecto que alguma doutrina mais recente procura alterar, com ponderosas razões. Ao longo deste texto procuramos analisar a presença do referido princípio quer na legislação nacional relativa ao Direito de Autor, quer nos principais instrumentos internacionais multilaterais, incluindo os mais significativos documentos relativos aos direitos humanos, bem como textos constitucionais. A abordagem é realizada mediante a análise de tópicos essenciais caracterizadores de matérias estruturais do domínio do Direito de Autor. O caminho analítico é percorrido com recurso a alguma da mais significativa doutrina, e, pontualmente, da jurisprudência relevante. Interessa-nos salientar as dimensões, positiva e negativa, ou seja, o modo como o Direito de Autor se construiu historicamente como incentivo fundamental à criação cultural, bem como discernir a existência de limites e exceções aos exclusivos legais estabelecidos. 


\section{COMENTÁRIOS E CONCLUSÕES}

Entende-se por norma todo uso que é preferencial e constante numa variedade de língua (cf. BECHARA, 2019, p.37), e isso vale tanto para seus falantes como para os que nela se manifestam por escrito. O levantamento das realizações linguísticas praticadas normalmente por uma comunidade linguística é o que Coseriu chama de "norma da língua" (1980, p.119-125). Também nos parece pertinente relembrar que a norma deve ser definida como uma medida que se leva em conta quando está em foco a individualidade de um texto. E também que ela (a norma) está circunscrita pelo contexto, o que inclui tempo, local e situação. Nesse caso se inserem os três textos apresentados, oriundos de páginas de livros acadêmicos escritos por profissionais que atuam no ambiente universitário, como dissemos, e que têm como predominante o modo de organização expositivo-argumentativo.

A leitura atenta e comparativa entre as formas original e "neutralizada" há-de confirmar a hipótese de que a tese da unidade dentro da diversidade é a que cabe reconhecer nesses casos. Não é nosso intuito discutir os motivos de termos, hoje, uma língua escrita padrão que reúne escolhas morfossintáticas comuns, desprovidas das marcas que são legítimas e estão presentes no dia a dia de cada uma dessas 
nações. O fato é que há entre esses usos, predominantemente orais, características que não estão ainda presentes na linguagem chamada "hegemônica", que para muitos - vou repetir velhos chavões - é a voz da classe dominante, fica ao lado do poder, é reduplicadora dos interesses da elite política ou econômica. Nesse sentido, não surpreende que a língua que as obras acadêmicas usam seja, gramaticalmente, mais conservadora do que inovadora, embora no campo lexical possamos encontrar, eventualmente, alguns "ares de originalidade e popularidade".

Apesar desses fatos, que - repito - não estão nos objetivos desta pesquisa, a realidade que temos é comum aos países onde o português é a língua oficial, é a língua a ser ensinada nas escolas a partir de um determinado padrão, tido por suas sociedades como o padrão a ser aprendido para que sua população tenha acesso aos bens culturais - a maior parte deles escrita justamente nessa modalidade de língua.

A descrição dos usos linguísticos praticados nos três exemplos aqui transcritos demonstrará a coerência e similaridade nas escolhas das estruturas sintáticas (sua ordenação oracional, seus conectivos) e dos aspectos morfológicos (seus usos verbais, pronominais, flexão e derivação), com alguma pequena variação de estilo ou de 
costume. Na superfície dos textos, como se vê nas versões originais, há a questão ortográfica e uma eventual escolha de palavras que, em cada contexto, são mais praticadas, mas isso não significa que um brasileiro não reconheça as palavras "desporto", "apoiantes", "adeptos", "camisolas" (texto I) ou que os textos II e III, que não têm marcas lexicais locais, gerem alguma dificuldade de compreensão.

Estes e outros aspectos incorporados/elucidados no curso da pesquisa podem contribuir para que se faça alguma revisão ou atualização nos capítulos de geo-história do português e de história interna nas obras de referência, mas também para a renovação do ensino dessa disciplina nos cursos de Letras e para a melhoria na formação dos futuros professores e pesquisadores de língua portuguesa.

\section{REFERÊNCIAS}

BECHARA, Evanildo (2019). Moderna Gramática Portuguesa. Rio de Janeiro: Nova Fronteira \& Lucerna.

COSERIU, Eugenio (1980). Lições de Linguística Geral. Rio de Janeiro: Ao Livro Técnico.

CUNHA, Celso Ferreira da (1985). A Questão da Norma Culta Brasileira. Rio de Janeiro: Tempo Brasileiro.

GONÇALVES, Nuno Manuel da Silva (2018). A Função Social do Direito de Autor. Cascais: Princípia.

HENRIQUES, Claudio Cezar (2019). Geo-História do Português: estudos sobre a história e a geografia do português na perspectiva brasileira. Rio de Janeiro: Gramma. 
(2018). Estilística e Discurso: estudos produtivos sobre texto e expressividade. Rio de Janeiro: AltaBooks.

HENRIQUES, Joana Gorjão (2017). O Racismo em Português: o lado esquecido do colonialismo. Rio de Janeiro: Tinta-da-China.

HODGES, Tony (2002). Angola: do Afro-Estalinismo ao Capitalismo Selvagem. Cascais: Principia.

MENÉNDEZ-PIDAL, Ramón (1964). “El Español de Canarias”. In Presente y Futuro de la Lengua Española. Madrid: Ed. Cultura Hispánica.

PINTO, Edith Pimentel (1992). A Língua Escrita no Brasil. São Paulo: Ática. PORTES, André (2017). O Profissional Incomum. Rio de Janeiro: Best Business.

QUIALA, Geraldo (2010). O Mundo Fantástico da Linguagem Desportiva. Luanda Sul: Mayamba.

ROSSI, Nelson (1980). "A Realidade Linguística Brasileira". Revista do Instituto de Estudos Brasileiros, 22.

WIPO - World Intellectual Property Organization (2010). Constituição da República de Angola. In https://www.wipo.int/edocs/lexdocs/laws/pt/ao/ ao001pt.pdf Acesso em 15.Jun.2020.

Claudio Cezar Henriques é Pós-Doutor em Letras pela Universidade de São Paulo (USP); Universidade do Estado do Rio de Janeiro (UERJ) e CNPq. Atua em na Graduação, no Mestrado e no Doutorado. É autor de GeoHistória do Português (2019), Estilística e Discurso (2018) e Morfologia (2014), entre outros. É membro do Grupo de Trabalho de Lexicologia, Lexicografia e Terminologia da ANPOLL e da Academia Brasileira de Filologia. Recebeu a medalha Isidoro de Sevilha em 2010. Sua área principal de interesse são a descrição e o ensino de Língua Portuguesa.

Lattes: http://lattes.cnpq.br/6265945306680129

Página pessoal: http://blogclaudiocezarhenriques.blogspot.com

E-mail: claudioch@uol.com.br 